\section{Physical and Hydraulic Properties of Commercial Pine-bark Substrate Products Used in Production of Containerized Crops}

\author{
James E. Altland ${ }^{1,4}$ \\ USDA-ARS, Application Technology Research Unit, Application Technology \\ Research Unit, Agricultural Engineering Building, 1680 Madison Avenue, \\ Wooster OH 44961
}

James S. Owen Jr. ${ }^{2}$ Department of Horticulture, Virginia Tech, Hampton Roads Agricultural Research and Extension Center, 1444 Diamond Springs Road, Virginia Beach, VA 23455

\author{
Brian E. Jackson ${ }^{2}$ \\ Department of Horticultural Science, North Carolina State University, 130 \\ Kilgore Hall, Raleigh, NC 27695

\begin{abstract}
Jeb S. Fields ${ }^{3}$
LSU AgCenter, Louisiana State University, Hammond Research Station, 21549 Old Covington Highway, Hammond, LA 70403
\end{abstract}

Additional index words. aged bark, air space, dynamic physical properties, evaporative method, fresh bark, particle size, Pinus taeda, porometer, sand, static physical properties, water holding capacity

\begin{abstract}
Pine bark is the primary constituent of nursery container media (i.e., soilless substrate) in the eastern United States. Pine bark physical and hydraulic properties vary depending on the supplier due to source (e.g., lumber mill type) or methods of additional processing or aging. Pine bark can be processed via hammer milling or grinding before or after being aged from $\leq 1$ month (fresh) to $\geq 6$ month (aged). Additionally, bark is commonly amended with sand to alter physical properties and increase bulk density $\left(D_{b}\right)$. Information is limited on physical or hydraulic differences of bark between varying sources or the effect of sand amendments. Pine bark physical and hydraulic properties from six commercial sources were compared as a function of age and amendment with sand. Aging bark, alone, had little effect on total porosity (TP), which remained at $\approx 80.5 \%$ (by volume). However, aging pine bark from $\leq 1$ to $\geq 6$ months shifted particle size from the coarse $(>2 \mathrm{~mm})$ to fine fraction $(<0.5 \mathrm{~mm})$, which increased container capacity (CC) $21.4 \%$ and decreased air space (AS) by $17.2 \%$ (by volume) regardless of source. The addition of sand to the substrate had a similar effect on particle size distribution to that of aging, increasing $C C$ and $D_{b}$ while decreasing AS. Total porosity decreased with the addition of sand. The magnitude of change in TP, AS, CC, and $D_{b}$ from a nonamended pine bark substrate was greater with fine vs. coarse sand and varied by bark source. When comparing hydrological properties across three pine bark sources, readily available water content was unaffected; however, moisture characteristic curves (MCC) differed due to particle size distribution affecting the residual water content and subsequent shift from gravitational to either capillary or hygroscopic water. Similarly, hydraulic conductivity (i.e., ability to transfer water within the container) decreased with increasing particle size.
\end{abstract}

In the eastern United States, nurseries use either loblolly pine (Pinus taeda L.) or longleaf pine (Pinus palustris Mill.) bark as the primary organic component in soilless substrates. Pine bark was initially used as a growing substrate in the 1970 s, with increasing acceptance due to its availability, favorable physical properties, and lack of detrimental chemical constituents when used to grow container crops. The harvesting, dilution or contamination with wood from other species, lumber mill and associated equipment, bark processing and storage practices can ultimately affect its physical properties and performance in containers, pine bark age, source, and type of sand for utilization as an amendment are among the most important and controllable factors affecting physical properties (Bilderback et al., 2005).

Pine bark age is classified by two seemingly binary terms: fresh or aged. However, both terms can include a continuous spectrum of age with no universally accepted definition of fresh vs. aged bark. Fresh pine bark is an identifiable, undecomposed organic matter that remains "relatively stable" due to high lignin content (Mauseth, 1988). Fresh pine bark continually changes physically and chemically and thus is not completely stable. A recent study concluded that physical properties will stabilize (degree of change lessened considerably) after 6 months of aging (Kaderabek, 2017). Buamscha et al. (2007) described fresh bark as material sold soon after tree debarking, grinding, and screening to size, whereas aged bark is material that goes through the same preparation process but sits in undisturbed piles ( 7 to $12 \mathrm{~m}$ tall) for an average of 7 months before use. Pokorny (1975) described the aging process as open-air stockpiling and weathering of bark, with no additions of fertilizer or lime to adjust $\mathrm{pH}$ and no effort to control moisture level. Pokorny (1975) furthermore suggested this process requires 3 to 18 months; thus, any bark that sits in these piles for less than 3 months would be considered fresh bark and anything longer than 3 months would be aged bark.

Limited research documents the physical or hydrological properties of, or differences in, pine bark as a function of age. Harrelson et al. (2004) grew cotoneaster (Cotoneaster dammeri C.K. Schneid. 'Skogholm') in fresh or aged (1 year) pine bark amended with three fertilizer rates. Cotoneaster were smaller in fresh pine bark, and differences in growth were attributed to lower water holding capacity in fresh bark compared with aged bark. In contrast, Cobb and Keever (1984) compared fresh and aged pine bark amended with a controlled-release nitrogen $(\mathrm{N})$ fertilizer, supplemented at four levels of N, and found that dwarf Japanese euonymus (Euonymus japonicus Thunb. 'Microphylla') and Japanese holly (Ilex crenata Thunb. 'Compacta') growth in fresh bark equaled or exceeded that in aged bark at all levels of supplemental N. The authors did not attribute measured plant responses to differences in substrate physical properties. Contrasting results in plant growth response to substrate physical properties are not surprising. No single substrate is suitable for all plant species (Lea-Cox and Smith, 1997). With respect to physical properties, plants respond more favorably to substrates that best mimic conditions (e.g., air and water availability) of their natural habitats.

Sand is the primary inorganic component added to pine bark in the southeast United States because of its low cost and availability. Coarse, sharp sands $(0.25-2 \mathrm{~mm})$ are recommended to be added to pine bark to increase 
$\mathrm{D}_{\mathrm{b}}$ (Reed, 1996), although the literature is not clear about the effects of sand on most physical properties. Jenkins and Jarrell (1989) developed models to predict physical properties of white fir bark [Abies concolor (Gordon \& Glend.) Lindl. ex Hildebr.] and fine sand. The resulting model predicted that AS would decrease and CC increase with increasing proportions of sand. They also report poor correlation between actual and predicted values for these two parameters. In contrast, Brown and Pokorny (1975) showed decreasing water percolation through pine bark and sand substrates with increasing proportion of sand. Decreased percolation in this context suggests that fine sand particles nested within the larger pores created by pine bark decreased AS while increasing CC and tortuosity. Bilderback et al. (2005) also reported, without statistics, that adding $20 \%$ (by volume) sand to pine bark decreases AS and increases $C C$ and $\mathrm{D}_{\mathrm{b}}$.

While pine bark physical properties have been addressed, physical properties are generally reported from a single source or only as background information on the treatments applied. The objective of this research was to provide an overview of pine bark physical properties from multiple commercial sources and describe these properties as a function of age or amendment with sand. Additionally, hydrological properties from three of the bark sources were compared to make greater inferences on container production.

\section{Materials and Methods}

Samples of fresh or aged loblolly pine bark were collected in May 2013 from the following commercial bark suppliers: Carolina Bark Products LLC (Seaboard, NC), Neuse Plant and Bark Inc. (Four Oaks, NC), Oldcastle Materials Inc. (Fuquay Varina, NC), Pacific Mulch Inc./Pacific Organics (Henderson, NC), Parker Bark Co. (Rose Hill, NC), and TH Blue Inc. (Eagle Springs, NC). Suppliers were not specifically identified in tables and figures due to privacy concerns. Samples were composites

Received for publication 15 Aug. 2018. Accepted for publication 15 Oct. 2018.

Funding for this work was provided, in part, by the Virginia Agricultural Experiment Stations, Agricultural Research Service, and the Hatch Programs of the National Institute of Food and Agriculture, U.S. Department of Agriculture.

Trade or brand names used in this publication do not constitute a guarantee or warranty of the products by Virginia Polytechnic Institute and State University, U.S. Department of Agriculture, North Carolina State University, or Louisiana State University and do not imply their approval to the exclusion of other products or vendors that may also be suitable.

${ }^{1}$ Research Horticulturist.

${ }^{2}$ Associate Professor.

${ }^{3}$ Assistant Professor.

${ }^{4}$ Corresponding author. E-mail: james.altland@ ars.usda.gov. of multiple subsamples from a single pine bark pile and were pulled from below the surface of the pile. Sampling and sample storage procedures were based on methods outlined in the U.S. Composting Council's Test Methods for the Examination of Composting and Compost (Thompson, 2002) and more thoroughly described by Kaderabek (2017). Briefly, stratified subsamples were taken from different heights (top, middle, and bottom) and horizontal depths (0.3, 0.6, 0.9 , and $1.2 \mathrm{~m}$ ) within each pile. At each sampling location, subsamples were taken by digging a hole to a depth of $1.2 \mathrm{~m}$ and removing $3 \mathrm{~L}$ of bark from the surface every $0.3 \mathrm{~m}$ (five subsamples). This sampling procedure accounts for variation within a pile and reduces possible errors due to stratification of constituents and conditions within the piles (Breitenbeck and Schellinger, 2004). Samples were stored indoors in sealed, $4 \mathrm{~mm}$ polyethylene bags at $4{ }^{\circ} \mathrm{C}$ to minimize moisture and microbial changes during storage. Aged and fresh bark had no fertilizer additions or $\mathrm{pH}$ adjustments and no attempts to control moisture level within the pile. The aging process of "aged" bark took place in open-air stockpiles at all six commercial producer sites. The bark handling and aging process varies by supplier because bark processors have no official regulated guidelines on how to handle and manage their supply inventories (Jackson, 2014).

Expt. 1. Pine bark samples were collected from each supplier and classified as fresh bark (aged less than 1 month), aging bark (aged 1 to 3 months), or aged bark (aged 6 months or more). Some suppliers, but not all, provided each of the three age classifications. Thus, data were analyzed by treating age as a random factor and supplier as a nested factor within age. There were three replications analyzed per sample collected.

Static physical properties, including TP, $\mathrm{CC}, \mathrm{AS}$, and $\mathrm{D}_{\mathrm{b}}$, were determined for each substrate using porometer analysis following procedures described in Fonteno and Harden (2010). In addition, particle size distribution of $100 \mathrm{~g}$ oven-dried samples were determined for three replicates of each substrate by passing the substrate through seven sieves (6.30-, 2.00-, 0.71-, 0.50-, 0.25-, 0.11-mm openings) and a lower catch pan. Sieves and pan were shaken for $5 \mathrm{~min}$ with a Ro-Tap shaker (Rx-29; W.S. Tyler, Mentor, OH). The particles that were retained on each sieve were weighed individually to determine particle size distribution. Particle sizes were then combined into three classifications following Drzal et al. (1999) and Puustjarvi and Robertson (1975): coarse $(>2.0 \mathrm{~mm})$, medium $(0.5-2.0 \mathrm{~mm})$, and fine $(<0.5 \mathrm{~mm})$.

Expt. 2. Coarse $(99 \%>0.5 \mathrm{~mm}$ by weight) and fine sand $(50 \%<0.5 \mathrm{~mm}$ by weight $)$ were obtained from TH Blue Inc (Eagle Spring, NC). Pine bark was collected from three suppliers, with each providing a source of either fresh or aged pine bark. Each substrate was blended with coarse or fine sand at $10 \%$ volume (Fig. 1). The same static physical properties previously described for Expt. 1 were conducted on these composite samples. There were three replications analyzed per pine bark age and sand-type combination.

Expt. 3. Static physical properties and hydraulic properties were determined for pine bark collected in 2016 from three separate sources. Moisture characteristic curves were developed for three pine bark samples collected via the evaporative method using a Hyprop (UMS, Munich, Germany) following the procedures described by Fields et al. (2017). Each substrate was packed to the same $D_{b}$ as for porometer analysis to ensure uniformity and mimic substrates in planted containers. Along with the relationship between volumetric water content (VWC) and water potential ( $\Psi$ ), the evaporative method provides estimates for the relationship between hydraulic conductivity (K) and both VWC and $\Psi$ for a given substrate. Data for each substrate were then compiled with HypropFit software (UMS, Munich, Germany) and TP (from porometer). With these added points included, data were then modeled (SAS v9.3, SAS Institute, Cary, $\mathrm{NC})$ to fit the constrained van Genuchten (1980) model as functions of VWC.

$$
\text { van Genuchten model: } \begin{aligned}
S e & =\frac{\theta-\theta r}{\theta s-\theta r} \\
= & {\left[1+(a|h|)^{n}\right]^{-\left(1-\frac{1}{n}\right)} }
\end{aligned}
$$

where Se represents effective saturation, $\theta$ represents VWC at both saturated $(\Theta \mathrm{s})$ and residual $\left(\Theta_{\mathrm{r}}\right)$ states, $\alpha$ and $\mathrm{n}$ are curve-fitting parameters, and $h$ is the pressure head. The parameter $\Theta_{\mathrm{s}}$ was equal to TP, and $\Theta_{\mathrm{r}}$ occurred at the point which increasing water potential no longer resulted in significant reductions in VWC (Stephens and Rehfeldt, 1985). Using the modeled MCC data, easily available water (EAW), the water held between -10 and -50 $\mathrm{hPa}$, and water buffering capacity (WBC), the water held between -50 and $-100 \mathrm{hPa}$ (de Boodt and Verdonck, 1972), were calculated for each of the three substrates. The MCC databased on effective saturation measured via the evaporative method were used along with the $\mathrm{K}(\Psi)$ measurements to fit a $\mathrm{K}(\Psi)$ model in HypropFit. This model predicted $\mathrm{K}$ across the measured tension range and weighted the actual $\mathrm{K}(\Psi)$ measurements to produce the strongest fit. The fit was computed (in HypropFit) with a nonlinear regression algorithm that minimized the sum of weighted squared residuals between model prediction (based on MCC measures) and measured $\mathrm{K}(\Psi)$ data.

Data presented in tables with associated statistics were subjected to analysis of variance or multivariate analysis of variance in JMP Pro (12.0.1, SAS Institute; Cary, NC) or SAS (SAS Institute), respectively, and means separated where appropriate using Tukey's honestly significant difference $(\alpha=0.05)$.

\section{Results and Discussion}

Expt. 1. Air space, CC, and TP were affected by pine bark age (Table 1). Air space was high in fresh bark relative to standards 

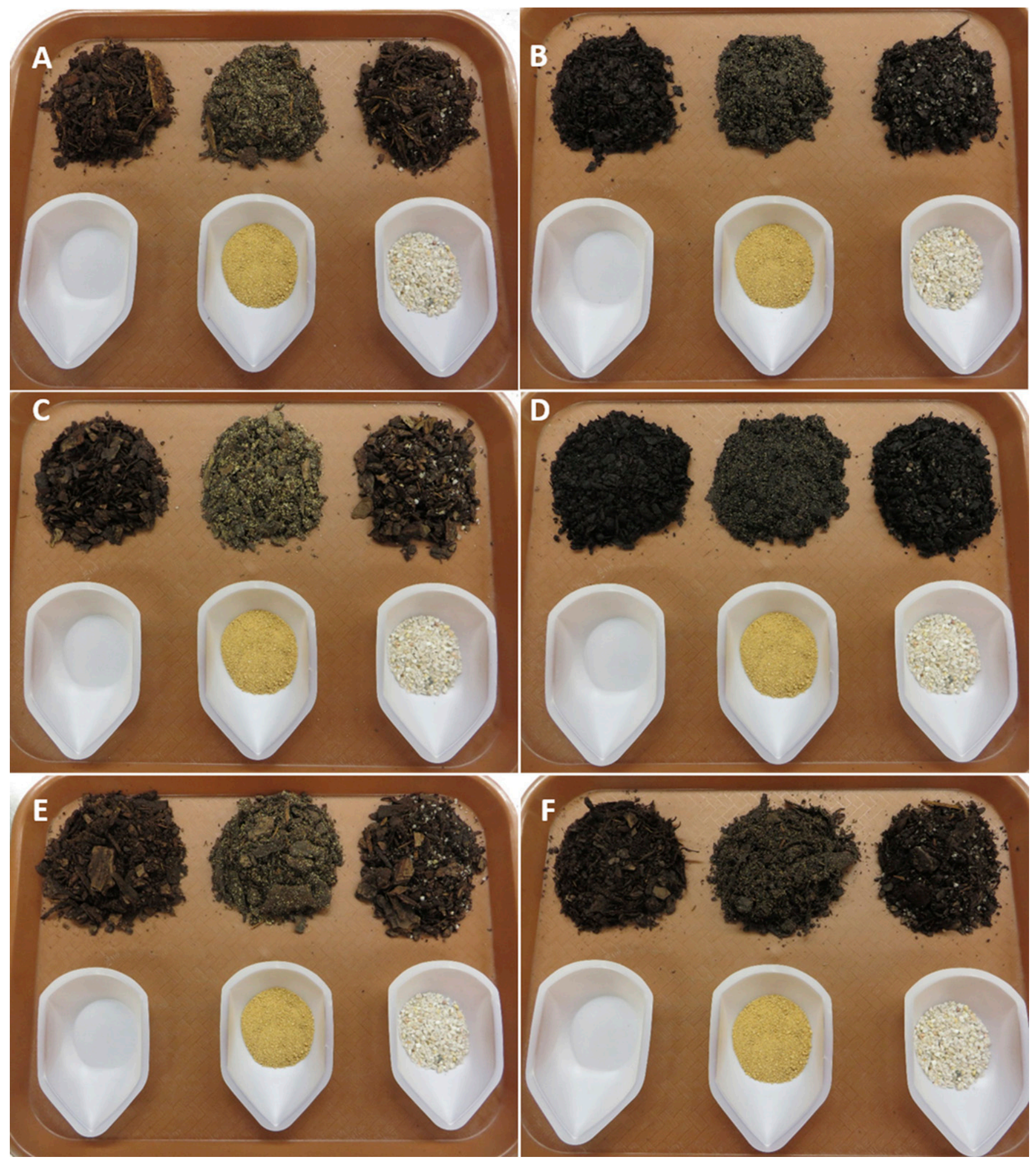

Fig. 1. Fresh (A) and aged (B) loblolly pine bark from supplier 1; fresh (C) and aged (D) loblolly pine bark from supplier 2; and fresh (E) and aged (F) loblolly pine bark from supplier 3. Bark of both ages from each supplier was amended with $10 \%$ (by volume) fine or coarse sand for determination of effects on physical properties.

for commercial potting mixes set by Bilderback et al. (2013), which state AS should range between $10 \%$ and $30 \%$. Although products within an age group affected AS $(P=0.0219)$, AS within the three broad categories of pine bark age were fairly consistent, with an average $\mathrm{CV}$ of $8.9 \%$. Air space was highest in fresh bark $(49.0 \%)$ and declined markedly in aging bark (39.4\%) and aged bark (31.8\%). Container capacity too was affected by pine bark age and product within age, and with a similarly low CV $(10 \%)$ for $\mathrm{CC}$ within an age group. In contrast to AS, $\mathrm{CC}$ increased with bark age with greater than $10 \%$ increase from fresh to aging bark, and from aging to aged bark. Total porosity, calculated as the sum of AS and CC, changed $4 \%$ (by volume) due to the inverse relation- ship between AS and CC that nullified net effect of bark age on TP. Total porosity was still affected by bark age $(P=0.0389)$ and increased slightly from $78.8 \%$ in fresh bark up to $82.6 \%$ in aged bark. This inverse relationship between AS and $\mathrm{CC}$ has been observed in other research evaluating pine bark amendments. Bilderback et al. (2005) reported that increasing rates of acrillite to a 
Table 1. Physical properties and particle size classification of 13 pine bark products from six sources categorized by age.

\begin{tabular}{|c|c|c|c|c|c|c|c|}
\hline \multirow[b]{3}{*}{ Source } & \multicolumn{4}{|c|}{ Static physical properties } & \multicolumn{3}{|c|}{ Substrate particle size } \\
\hline & AS & $\mathrm{CC}$ & TP & \multirow{2}{*}{$\frac{\mathrm{D}_{\mathrm{b}}}{\left(\mathrm{g} / \mathrm{cm}^{3}\right)}$} & Coarse $>2 \mathrm{~mm}$ & Medium $2.0-0.5 \mathrm{~mm}$ & Fine $<0.5 \mathrm{~mm}$ \\
\hline & \multicolumn{3}{|c|}{ 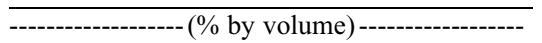 } & & \multicolumn{3}{|c|}{ 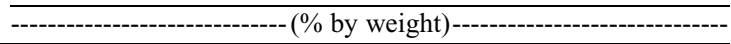 } \\
\hline & \multicolumn{7}{|c|}{ Fresh bark, aged $\leq 1 \mathrm{mo}$} \\
\hline 1 & 38.9 & 40.7 & 79.6 & 0.16 & 54.1 & 27.0 & 16.8 \\
\hline 2 & 50.5 & 29.3 & 79.8 & 0.14 & 73.5 & 17.6 & 8.9 \\
\hline 3 & 54.2 & 19.3 & 73.6 & 0.14 & 90.9 & 7.0 & 2.0 \\
\hline 4 & 48.8 & 31.4 & 80.3 & 0.17 & 63.0 & 25.0 & 12.0 \\
\hline 5 & 52.4 & 28.6 & 80.9 & 0.14 & 85.6 & 7.5 & 5.8 \\
\hline \multirow[t]{2}{*}{$\overline{\mathrm{x}} \pm \sigma_{\overline{\mathrm{x}}}$} & $49.0 \pm 2.7$ & $29.9 \pm 3.4$ & $78.8 \pm 1.3$ & $0.15 \pm 0.01$ & $73.4 \pm 6.9$ & $16.8 \pm 4.2$ & $9.1 \pm 2.5$ \\
\hline & \multicolumn{7}{|c|}{ Aging bark, aged 1-3 mo. } \\
\hline 6 & 45.1 & 35.0 & 80.1 & 0.17 & 59.1 & 27.0 & 13.8 \\
\hline 7 & 33.7 & 46.4 & 80.1 & 0.16 & 67.6 & 21.7 & 10.6 \\
\hline \multirow[t]{2}{*}{$\overline{\mathrm{x}} \pm \sigma_{\overline{\mathrm{x}}}$} & $39.4 \pm 5.7$ & $40.7 \pm 5.7$ & $80.1 \pm 0.0$ & $0.17 \pm 0.01$ & $63.4 \pm 4.3$ & $24.3 \pm 2.7$ & $12.21 \pm 1.6$ \\
\hline & \multicolumn{7}{|c|}{ Aged bark, aged $\geq 6$ mo. } \\
\hline 8 & 29.9 & 52.1 & 82.1 & 0.17 & 54.4 & 28.3 & 17.3 \\
\hline 9 & 22.5 & 59.9 & 82.4 & 0.18 & 33.5 & 44.2 & 22.2 \\
\hline 10 & 33.2 & 50.3 & 83.5 & 0.15 & 60.4 & 28.0 & 11.5 \\
\hline 11 & 36.7 & 44.7 & 81.4 & 0.19 & 44.1 & 33.8 & 22.1 \\
\hline 12 & 36.3 & 45.3 & 81.5 & 0.17 & 46.9 & 34.8 & 17.3 \\
\hline 13 & 32.0 & 52.4 & 84.5 & 0.15 & 63.0 & 24.7 & 12.3 \\
\hline \multirow[t]{2}{*}{$\overline{\mathrm{x}} \pm \sigma_{\overline{\mathrm{x}}}$} & $31.8 .0 \pm 2.1$ & $50.8 \pm 2.3$ & $82.6 \pm 0.5$ & $0.17 \pm 0.01$ & $50.4 \pm 4.5$ & $32.3 \pm 2.8$ & $17.1 \pm 1.9$ \\
\hline & \multicolumn{7}{|c|}{$P$ value } \\
\hline Age & 0.0024 & 0.0016 & 0.0389 & 0.1039 & 0.0448 & 0.0623 & 0.0618 \\
\hline Product (age) & 0.0219 & 0.0159 & 0.1576 & 0.0147 & 0.0142 & 0.0150 & 0.0195 \\
\hline
\end{tabular}

$\mathrm{AS}=$ air space; $\mathrm{CC}=$ container capacity; $\mathrm{D}_{\mathrm{b}}=$ bulk density; $\mathrm{TP}=$ total porosity.

pine bark substrate caused a linear decrease in AS with a concomitant increase in $\mathrm{CC}$ and no change in TP. Bulk density increased from 0.15 to $0.17 \mathrm{~g} \cdot \mathrm{cm}^{-3}(P=0.1039)$ with variation by source within each age group $(P=0.0147)$. This agrees with Bilderback et al. (2005), who showed that pine bark $D_{b}$ increased when aged for 1 year compared with fresh bark. It also agrees with Harrelson et al. (2004), who showed that pine bark aged for 1 year had lower AS, greater $C C$ and $D_{b}$, and similar TP compared with fresh pine bark. They concluded Cotoneaster dammeri 'Skogholm' growth in a fresh pine bark was reduced compared with plants grown in aged pine bark due to lower CC of fresh bark.

Pine bark particle size, within all three size fractions, was affected by age $(P<$ $0.0623)$ and source within age $(P<0.0195$; Table 1). Differences in particle size from one source to another is to be expected due to the many ways of grinding, screening, and managing bark piles. It was observed (by these authors) during the sample collection stage of this study that bark producers (sources) handle raw bark differently once it arrives at their facility from the saw/lumber mills. In some instances, the raw bark was immediately hammer milled through small screens resulting in finer particled bark that was then windrowed for aging. At other bark producers, the raw bark arrived on site and was then coarsely milled to separate large pine bark nuggets, mini nuggets, and fines. The nuggets were to be sold separately as a bulk or bagged landscape mulch material. The remaining fines were then windrowed for aging. The removal of nuggets before milling most likely is the reason for the particle size variation observed among sources. Pokorny (1979) also showed that pine bark particle size distribution "varied considerably" from six commercial sources. Percent coarse particles decreased as pine bark aged from fresh to aged $(P=0.0448)$. Conversely, percent of medium and fine particles increased with bark age $(P=0.0623$ and 0.0618 , respectively). Buamscha et al. (2007) previously reported a significant, albeit minor, reduction in particle size in aged vs. fresh douglas fir (Psuedotsuga menziesii Mirb.) bark. Pokorny (1979) suggested that pine bark containing $70 \%$ to $80 \%$ (by volume) coarse particles (0.6-9.5 $\mathrm{mm}$ in diameter) and $20 \%$ to $30 \%$ (by volume) fine particles $(<0.6 \mathrm{~mm})$ makes a suitable potting substrate. By this standard, none of the pine bark materials in our study classified as fresh were suitable; however, four of the six sources aged for 6 months or more were within or close to the standard proposed by Pokorny (1979) (Table 1).

Our data show that as pine bark ages, particle size decreases, resulting in less AS, greater $\mathrm{CC}$, and greater $\mathrm{D}_{\mathrm{b}}$, with little or no change to overall TP. Others have reported that bark aging reduces particle size (Buamscha et al., 2007; Fields, et al., 2013; Pokorny, 1979). The decrease in particle sizes over time can likely be attributed to microbial degradation during aging and breakage due to the turning process with front-end bucket loaders. The frequency and method of pine bark pile turning (which was not determined in the scope of this study) among the six sources may also explain variances observed. Lea-Cox and Smith (1997) also showed, with a series of substrates constructed from specific fractions, that increasing fine particles resulted in decreasing AS and increasing CC. Likewise, Jackson et al. (2010) demonstrated that decreasing a hammermill screen size when generating a pine tree substrate resulted in increasingly greater percentages of fine particles and lower percentages of coarse particles. In that work, decreasing the hammermill screen size also caused AS to decrease quadratically and $\mathrm{CC}$ to increase quadrati- cally with decreasing screen size, whereas TP was similar across screen sizes.

Expt. 2. The main effects of pine bark age, sand type, and source affected all the measured physical properties (except TP) either alone or in interaction (Table 2). Air space was affected by the interactions of pine bark age $\times$ sand type $(P=0.0154)$ and pine bark age $\times$ source $(P=0.0002)$. In both cases, AS decreased with increasing pine bark age. Considering the pine bark age $\times$ sand type interaction, fine sand resulted in the lowest AS in both pine bark age treatments, followed by coarse sand with intermediate values of AS and pine bark with no sand having the highest AS in both age groups. Although AS decreased for all bark sources with increasing pine bark age, one source (C) decreased less, thus resulting in the significant pine bark age $\times$ source interaction. Container capacity was affected by the main effect of sand type $(P=$ $0.0081)$ and the interaction of pine bark age $x$ source (0.0048); in all cases, CC increased with increasing bark age. Averaging across pine bark age and source, CC was highest with fine sand $(47.5 \%)$ and similar with coarse or no sand $(43.6 \%)$. Similar to AS, the interaction of pine bark age $\times$ source was caused by one source $(\mathrm{C})$ increasing at a different rate compared with the other sources. Total porosity was affected only by sand type $(P=0.0001)$. Pine bark with no sand had greater TP $(85.1 \%)$ than pine bark with coarse or fine sand $(77.8 \%)$. Total porosity increased slightly with pine bark age $(78.5 \%$ to $82.0 \%, P=0.0623$ ), although the differences were less pronounced compared with $\mathrm{AS}$ or $\mathrm{CC}$ due to the aforementioned inverse relationship between AS and CC. Bulk density was affected by sand type $(P=0.0001)$ and the interaction of pine bark age $\times$ source $(P=0.0236)$. Averaged across pine bark age and sources, $D_{b}$ of pine bark alone (without sand) was $0.16 \mathrm{~g} \cdot \mathrm{cm}^{-3}$, whereas those with 
either sand type had more than double the bulk density $\left(0.34 \mathrm{~g} \cdot \mathrm{cm}^{-3}\right)$. Bilderback et al. (2005) similarly reported that adding 20\% (by volume) sand to pine bark increased $D_{b}$ from 0.19 to $0.45 \mathrm{~g} \cdot \mathrm{cm}^{-3}$. Considering the pine bark age $\times$ source interaction and averaging over sand treatment, $D_{b}$ of all substrates increased with increasing age, although source B increased more than the others. These data corroborate the primary findings in Expt. 1, in that AS decreases with bark age while $C C$ and $D_{b}$ increase with age. The overall impact of sand was to decrease AS, while increasing $C C$ and $D_{b}$. Bilderback et al. (2005) also reported the same influence of sand on aged pine bark that had been screened below $1.25 \mathrm{~cm}$. The effect of sand type (fine or coarse) and percent of its incorporation on the resulting physical properties of a bark substrate is also likely dependent on the particle size of the bark it is being added to. Regardless of age, the particle sizes and range of sizes of bark would influence how sand settled or nested inside when added, thus influencing air and water capacities differently.

The three particle size classifications were affected by either a three-way interaction
(2.0-0.5 mm, $P=0.0160)$ or the pine bark age $\times$ sand and pine bark age $\times$ source interactions $(>2.0 \mathrm{~mm}$ and $<0.5 \mathrm{~mm}, P<$ 0.0498 , Table 2). The percentage of coarse particles decreased with increasing pine bark age, and interactions with sand or source were merely differences in the rate of change among sources. Likewise, the percentage of medium and fine particles increased with increasing pine bark age with only minor differences in the rate of change between sand treatment and sources causing significant interactions. The fine sand increased the percentage of fine particles and decreased the percentage of medium and coarse particles across both bark age groups, while coarse sand caused only minor differences compared with pine bark with no sand.

These data show that bark particle size reduction from pine bark aging or inclusion of sand will cause a decrease in AS and an increase in CC and $\mathrm{D}_{\mathrm{b}}$. Richards et al., (1986) similarly concluded that either pine bark fines or the inclusion of a sandy loam soil in a bark substrate decreased the overall particle size distribution with a concomitant decrease in AS and increase in CC. This relationship between particle size and physical properties
(AS, CC, and $\mathrm{D}_{\mathrm{b}}$ ) is not unique to pine bark and sand amendments. Bachman and Metzger (2007) demonstrated that a commercial substrate (Metromix 360, The Scotts Co., Marysville, $\mathrm{OH}$ ) amended with increasing ratios of vermicompost from $10 \%$ to $100 \%$ (by vol.) had increasing proportion of fine particles, increasing CC (from $40 \%$ to $57 \%$, respectively), decreasing AS (from $52 \%$ to $35 \%$, respectively), and lower but more stable $\mathrm{TP}$ (93\% to $91 \%$, respectively).

Expt. 3. Air space differed with each pine bark source (Table 3 ), and all had greater than the maximum recommended AS $(10 \%$ to $30 \%$; Bilderback et al., 2013). Pine bark from sources $\mathrm{X}$ and $\mathrm{Y}$ were similar and within the recommended range for $\mathrm{CC}(45 \%$ to $65 \%$; Bilderback et al. 2005), while that from source $\mathrm{Z}$ did not fall within the recommended range for $\mathrm{CC}$. Total porosity for all three sources were similar $(<2 \%$ difference between any two sources). The inverse relationship between AS and $\mathrm{CC}$ and resulting stability of TP across treatments or sources is similar to that observed in Expts. 1 and 2. Pine bark $D_{b}$ was highest in source $X$, while source $\mathrm{Y}$ and $\mathrm{Z}$ had lower and similar pine bark $D_{b}$. All pine bark samples collected in

Table 2. Physical properties and particle size classification of pine bark substrates, either fresh $(<1 \mathrm{mo})$ or aged ( $>6$ mo), with three sand amendments, and from three commercial sources.

\begin{tabular}{|c|c|c|c|c|c|c|c|c|c|}
\hline \multirow{2}{*}{ Age (mo.) } & \multirow{2}{*}{ Sand } & \multirow{2}{*}{ Bark source } & \multirow{2}{*}{\multicolumn{3}{|c|}{ 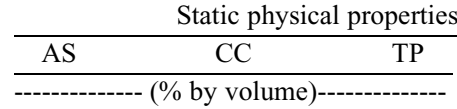 }} & & \multicolumn{3}{|c|}{ Substrate particle size } \\
\hline & & & & & & $\frac{D_{b}}{\left(\mathrm{~g} / \mathrm{cm}^{3}\right)}$ & $>2 \mathrm{~mm}$ & $2.0-0.5 \mathrm{~mm}$ & $<0.5 \mathrm{~mm}$ \\
\hline \multirow[t]{6}{*}{$\overline{s 1}$} & None & $\mathrm{A}$ & 45.9 & 38.5 & 84.3 & 0.15 & 71.5 & 21.9 & 6.6 \\
\hline & & $\mathrm{C}$ & 41.0 & 42.7 & 83.7 & 0.15 & 75.4 & 19.7 & 6.7 \\
\hline & Coarse & A & 41.7 & 36.2 & 78.0 & 0.32 & 63.5 & 33.1 & 3.5 \\
\hline & & B & 50.0 & 26.6 & 76.6 & 0.30 & 75.8 & 22.3 & 1.8 \\
\hline & & $\mathrm{C}$ & 36.7 & 37.4 & 74.2 & 0.31 & 71.1 & 26.1 & 2.9 \\
\hline & & $\mathrm{C}$ & 29.1 & 44.4 & 73.4 & 0.35 & 34.6 & 41.2 & 24.3 \\
\hline \multirow[t]{6}{*}{$\geq 6$} & None & A & 30.7 & 57.3 & 88.0 & 0.17 & 60.8 & 27.8 & 11.5 \\
\hline & & B & 37.0 & 47.4 & 84.4 & 0.19 & 48.1 & 38.9 & 13.0 \\
\hline & & $\mathrm{C}$ & 34.2 & 52.0 & 86.3 & 0.16 & 66.1 & 24.0 & 11.1 \\
\hline & Coarse & A & 23.4 & 58.0 & 81.4 & 0.33 & 62.9 & 30.8 & 6.4 \\
\hline & & B & 29.7 & 48.1 & 77.8 & 0.35 & 55.2 & 36.6 & 8.2 \\
\hline & & $\mathrm{C}$ & 28.4 & 52.2 & 80.6 & 0.33 & 69.5 & 26.8 & 3.9 \\
\hline \multicolumn{3}{|l|}{ Source } & 0.3431 & 0.1965 & 0.2901 & 0.7711 & 0.7098 & 0.6946 & 0.9045 \\
\hline \multicolumn{3}{|l|}{ Age } & 0.0723 & 0.0305 & 0.0623 & 0.1511 & 0.1890 & 0.2357 & 0.1505 \\
\hline \multicolumn{3}{|l|}{ Sand } & 0.0001 & 0.0081 & 0.0001 & 0.0001 & 0.0007 & 0.0002 & 0.0001 \\
\hline \multicolumn{3}{|c|}{ Source $\times$ age } & 0.0002 & 0.0048 & 0.0889 & 0.0236 & 0.0097 & 0.0352 & 0.0012 \\
\hline \multicolumn{3}{|c|}{ Source $\times$ sand } & 0.3871 & 0.5069 & 0.6362 & 0.5964 & 0.6035 & 0.5858 & 0.1109 \\
\hline \multicolumn{3}{|c|}{ Age $\times$ sand } & 0.0154 & 0.1238 & 0.1839 & 0.4513 & 0.0498 & 0.1678 & 0.0083 \\
\hline \multicolumn{3}{|c|}{ Source $\times$ age $\times$ sand } & 0.9368 & 0.3986 & 0.6751 & 0.3314 & 0.1326 & 0.0160 & 0.9788 \\
\hline
\end{tabular}

$\mathrm{AS}=$ air space $\mathrm{CC}=$ container capacity; $\mathrm{D}_{\mathrm{b}}=$ bulk density; $\mathrm{TP}=$ total porosity.

Table 3. Physical properties and particle size classification of three bark sources measured for hydraulic properties (Figs. 1 and 2).

\begin{tabular}{|c|c|c|c|c|c|c|c|c|}
\hline \multirow{2}{*}{ Source } & \multicolumn{5}{|c|}{ Static physical properties } & \multicolumn{3}{|c|}{ Substrate particle size } \\
\hline & AS & $\mathrm{CC}$ & Available water & $\mathrm{TP}$ & $\frac{D_{b}}{\left(\mathrm{~g} / \mathrm{cm}^{3}\right)}$ & Coarse $>2 \mathrm{~mm}$ & Medium $2.0-0.5 \mathrm{~mm}$ & Fine $<0.5 \mathrm{~mm}$ \\
\hline$\overline{\mathrm{X}}$ & $31.0 \mathrm{c}^{\mathrm{z}}$ & $49.0 \mathrm{a}$ & 27.8 & 79.9 & $0.17 \mathrm{a}$ & $52.5 \mathrm{~b}$ & $31.6 \mathrm{a}$ & $16.0 \mathrm{a}$ \\
\hline Z & $39.8 \mathrm{a}$ & $39.7 \mathrm{~b}$ & 27.4 & 79.5 & $0.15 \mathrm{~b}$ & $72.2 \mathrm{a}$ & $15.5 \mathrm{~b}$ & $12.3 \mathrm{~b}$ \\
\hline$P$ value & $<0.0001$ & 0.0002 & 0.4408 & 0.0611 & 0.0002 & $<0.0001$ & 0.0002 & $<0.0001$ \\
\hline
\end{tabular}

${ }^{\mathrm{z}}$ Means with different letters within a column are significantly different according to Tukey's honestly significant difference test.

$\mathrm{AS}=$ air space $\mathrm{CC}=$ container capacity; $\mathrm{D}_{\mathrm{b}}=$ bulk density; $\mathrm{TP}=$ total porosity. 
Expts. 1-3 (excluding those with sand) had $\mathrm{D}_{\mathrm{b}}$ lower than the recommended range of 0.19 to $0.70 \mathrm{~g} / \mathrm{cm}^{3}$ (Bilderback et al., 2013); however, the Southern Nursery Association standards are for substrate composites, while the pine bark samples in these experiments were single components. Commercial nursery growers often combine pine bark with substrate components such as sand or peat moss to produce a suitable growing medium (Barrett et al., 2016). The inclusion of sand, peat moss, or similar constituents typically reduce AS and increase $C C$ and $D_{b}$ to fit within the standards (Bilderback et al., 2013), as shown by Gabriel et al., (2009). Bark source had no effect on AW $(P=0.4408)$ at $-1.5 \mathrm{MPa}$ using a pressure plate extractor.

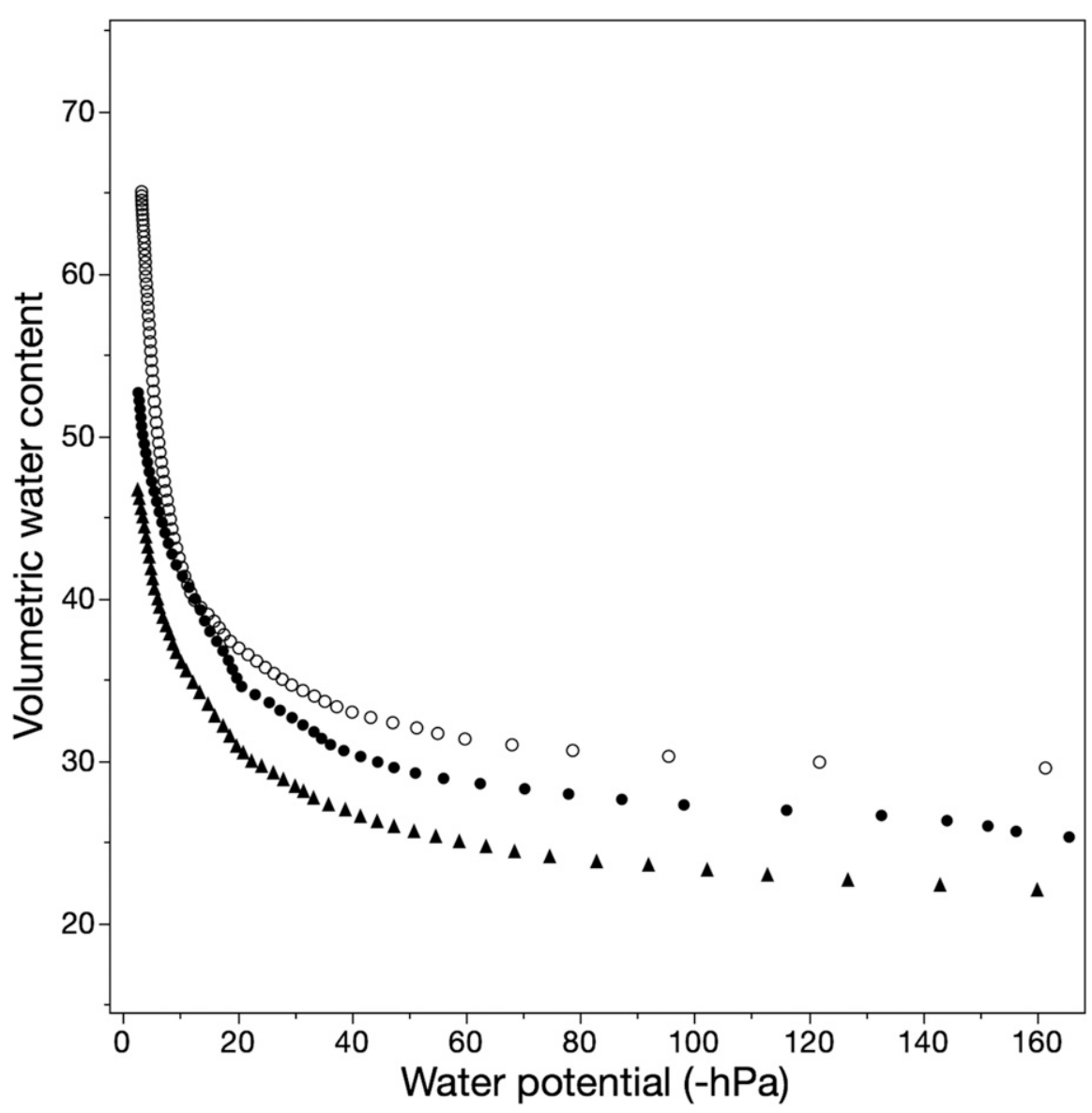

Fig. 2. Observed relationship of volumetric water content and water potential generated via the evaporative method to fit moisture characteristic parameters of aged pine bark from three sources $[X(=), Y(\Lambda), Z$ (o)] that provide soilless substrate for containerized crop production in the eastern United States.
The three bark sources had distinct MCC (Fig. 2). The TP values from Table 3 were used for each substrate to fit the van Genuchten moisture release models, and thus the $\Theta_{\text {s }}$ values were equal to TP (Table 4; Fig. 2), with miniscule change due to curve fit. The models predict a $\theta_{\mathrm{r}}$ value for the pine bark from source $Y$ to be about twice as high as in the pine bark from sources $\mathrm{X}$ and $\mathrm{Z}$. The highest $\theta r$ value was from the bark with the lowest percentage of fine-sized particles. There was substantially less capillary water (water held in pores between particles) in substrates composed of large-particle materials. Increased particle size shifts pore space toward gravitational pores as opposed to capillary and hygroscopic. These gravitational pores drain more readily, thus bark from source $\mathrm{Y}$ will likely expend the plant available water at greater water potentials than bark from source $\mathrm{X}$ and $\mathrm{Z}$. Fine particles increase pore uniformity. We observed a gradual decrease in VWC as water potential decreased. Bark from all three sources were similar in regard to EAW and WBC, which demonstrates that there was little difference in readily available water (water held at tensions $\geq 100 \mathrm{hPa}$ ) between the bark sources, with less than $2.5 \%$ by volume between the highest and lowest bark (Table 4). In fact, there was less than $10 \%$ difference in VWC, the lowest optimal water potential $(-100 \mathrm{hPa})$ between all three bark sources.

Pine bark K curves (Fig. 3) revealed how readily water is distributed within the pine bark. There was a gradual reduction of $\mathrm{K}$ as the substrate dried within the range of readily available water for source $Y$, alluding to the ability of this bark to continue to conduct water at a higher rate compared with the other bark sources when used under normal growing conditions (Campbell and Campbell, 1982). The most rapid reduction of $\mathrm{K}$ was observed in the bark from source $X$, which may limit water movement and plant water uptake (O'Meara et al., 2014). Conversely, bark from source $\mathrm{X}$ can continue conducting water at lower VWC. Particle size distribution had a major influence on substrate $\mathrm{K}$. Substrates with a greater percent of coarse particles lose more mobile water at high water potentials due to increased percent of gravitational pores. Loss of mobile water causes the asymptotic relationship between VWC and $\mathrm{K}$ to occur at greater VWC with a greater percent of coarse particles. As particle

Table 4. Hydraulic properties of pine bark from three sources attained from evaporative measure data fit to van Genuchten moisture retention models.

\begin{tabular}{|c|c|c|c|c|c|c|c|c|}
\hline & $\theta_{\mathrm{r}}^{\mathrm{z}}$ & $\theta_{\mathrm{s}}^{\mathrm{y}}$ & \multirow{2}{*}{$\frac{\text { Alpha }^{\mathrm{x}}}{\mathrm{cm}^{-1}}$} & \multirow[b]{2}{*}{$\mathrm{n}^{\mathrm{w}}$} & \multirow[b]{2}{*}{$r^{2 v}$} & $\mathrm{EAW}^{\mathrm{u}}$ & $\mathrm{WBC}^{\mathrm{t}}$ & $>100 \mathrm{hPa}^{\mathrm{s}}$ \\
\hline Product & $\overline{----\cdot-}$ & 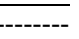 & & & & \multicolumn{3}{|c|}{ - $\mathrm{cm}^{3} \cdot \mathrm{cm}^{-3}$} \\
\hline $\bar{X}$ & 0.175 & 0.799 & 1.4476 & 1.3703 & 0.9946 & 11.79 & 1.96 & 26.96 \\
\hline Y & 0.281 & 0.833 & 0.3692 & 1.9664 & 0.9862 & 9.56 & 1.75 & 29.92 \\
\hline
\end{tabular}

${ }^{\mathrm{z}}$ Volumetric water content of the point where reduction in water potential no longer results in loss of water.

${ }^{\mathrm{y}}$ Volumetric water content at saturation.

${ }^{x}$ Parameter indicative of the inverse of the air entry value.

${ }^{\mathrm{w}}$ Unitless curve fitting parameter associated with pore distribution (curve shape).

${ }^{\mathrm{v}}$ Goodness of fit measure for the tension data to the van Genuchten model.

${ }^{\mathrm{u}}$ Easily available water is water held between water potentials of -10 and $-50 \mathrm{hPa}$.

${ }^{t} \mathrm{Water}$ buffering capacity is water held between water potential of -50 and $-100 \mathrm{hPa}$.

${ }^{\mathrm{s}}$ Water held at water potentials lower than $-100 \mathrm{hPa}$. 


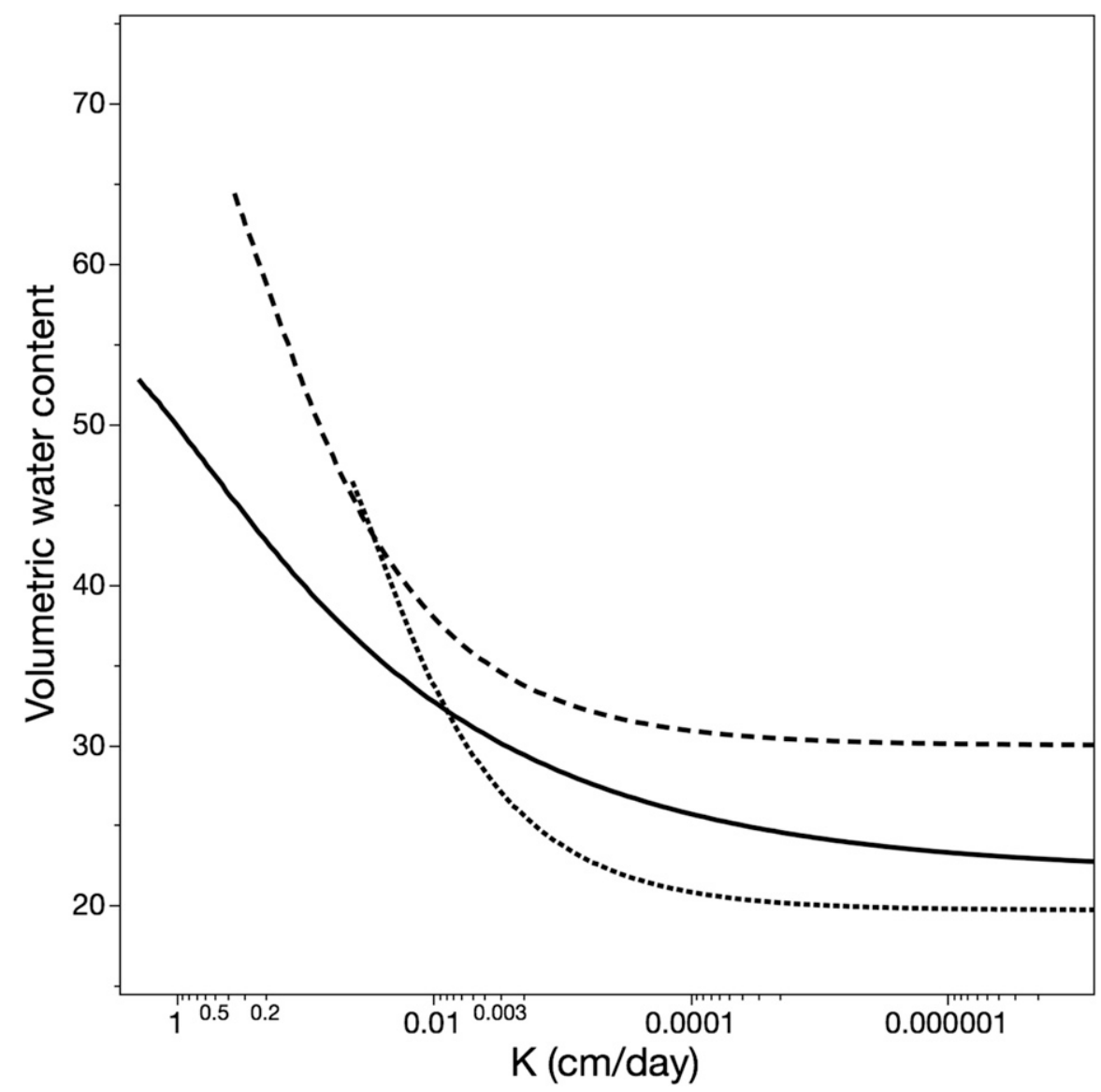

Fig. 3. Modeled unsaturated hydraulic conductivity (K) of aged pine bark (Pinus taeda) from three North Carolina bark sources $[\mathrm{X}(-), \mathrm{Y}(\cdots), \mathrm{Z}(---)]$ that provide soilless substrate for containerized crop production in the eastern United States.

size is reduced, the plateau of $\mathrm{K}$ will occur at reduced VWC, allowing water to continue to be translocated within the substrate at lower water potentials. Therefore, bark from source X, although not able to conduct water as rapidly as bark from $\mathrm{Y}$ and $\mathrm{Z}$ under normal growing conditions, can continue to move water at a more rapid rate under drier conditions than bark from source $\mathrm{Y}$ and $\mathrm{Z}$, demonstrating that source $\mathrm{X}$ is better suited for use in low water production systems (Fields et al., 2017). This shows the importance of bark properties on designing or revising irrigation schedules.

Properties of the pine bark from the three sources were similar in regard to many of the measured physical properties (TP, AW, EAW, and WBC), although subtle differences in the physical makeup of each bark were observed (Fields et al., 2013; Pokorny, 1975). These differences in bark physical and hydrologic properties are attributed to differences in source material, processing, and cultural management of inventory (personal observation by these authors; Bilderback et al., 2005). Although pine bark static physical properties were similar across the three sources, we saw pronounced differences in the moisture release characteristic and hydraulic conductivity curves, which represent measures of the various barks' hydrologic makeup. Differences in pine bark hydrology affect water availability (Fields et al., 2017) and solute transport and should
Barrett, G.E., P.D. Alexander, J.S. Robinson, and N.C. Bragg. 2016. Achieving environmentally sustainable growing media for soilless plant cultivation systems-A review. Scientia Hort. 212:220-234.

Bilderback, T.E. 1987. Effect of particle size and aging on moisture retention of pine bark nursery mulches. Proc. Southern Nurs. Assoc. Res. Conf. 32:49-53.

Bilderback, T.E. 2000. Pine bark handling and storage. North Carolina State Department of Horticultre Science Nursery Crops. <http:// www.nurserycropscience.info/substrates/manageinventory/extension-pubs/pine-bark-storage-andhandling.doc/view>.

Bilderback, T., C. Boyer, M. Chappell, G. Fain, D. Fare, C. Gilliam, B.E. Jackson, J. Lea-Cox, A.V. LeBude, A. Niemiera, J. Owen, J. Ruter, K. Tilt, S. Warren, S. White, T. Whitwell, R. Wright, and T. Yeager. 2013. Best management practices: Guide for producing nursery crops. 3rd ed. Southern Nurs. Assn., Acworth, GA.

Bilderback, T.E., S.L. Warren, J.S. Owen, Jr., and J.P. Albano. 2005. Healthy substrates need physicals too! HortTechnology 15:747-751.

Breitenbeck, G.A. and D. Schellinger. 2004. Calculating the reduction in material mass and volume during composting. Compost Sci. Util. 12(4):365-371.

Brown, E.F. and F.A. Pokorny. 1975. Physical and chemical properties of media composed of milled pine bark and sand. J. Amer. Soc. Hort. Sci. 100:119-121.

Buamscha, M.G., J.E. Altland, D.M. Sullivan, D.A. Horneck, and J. Cassidy. 2007. Chemical and physical properties of Douglas fir bark relevant to the production of container plants. HortScience 42:1281-1286.

Campbell, G.S. and M.D. Campbell. 1982. Irrigation scheduling using soil moisture measurements: theory and practice. Adv. Irr. 1:25-42.

Cobb, G.S. and G.J. Keever. 1984. Effects of supplemental $\mathrm{N}$ on plant growth in fresh and aged pine bark. HortScience 19:127-129.

de Boodt, M. and O. Verdonck. 1972. The physical properties of substrates in horticulture. Acta Hort. 26:37-44.

Drzal, M.S., W.C. Fonteno, and D.K. Cassel. 1999. Pore fraction analysis: A new tool for substrate testing. Acta Hort. 481:43-54.

Fields, J.S., J.S. Owen, Jr., and H.L. Scoggins. 2017. The influence of substrate hydraulic conductivity on plant water status of an ornamental container crop grown in suboptimal substrate water potentials. HortScience 52:1419 1428.

Fields, J.S., W.C. Fonteno, and B.E. Jackson. 2013. Pine bark physical properties influenced by bark source and age. Acta Hort. 1055:423426.

Fonteno, W.C. and C.T. Harden. 2010. North Carolina State University Horticultural Substrates Lab Manual. North Carolina State University.

Gabriel, M.Z., J.E. Altland, and J.S. Owen, Jr. 2009. The effect of physical and hydraulic properties of peatmoss and pumice on Douglas fir bark based soilless substrates. HortScience 44:874-878.

Harrelson, T., S.L. Warren, and T.E. Bilderback. 2004. How do you manage aged versus fresh pine bark? Proc. Southern Nurs. Assoc. Res. Conf. 49:63-66.

Hoskins, T., J.S. Owen, Jr., J.S. Fields, J.E. Altland, Z. Easton, and A. Niemiera. 2014. Solute transport through a pine-bark based substrate under saturated and unsaturated conditions. J. Amer. Soc. Hort. Sci. 139:634-641. 
Jackson, B.E. 2014. Substrate discrepancies. Nurs. Mgt. 30:14-16.

Jackson, B.E., R.D. Wright, and M.C. Barnes. 2010. Methods of constructing a pine tree substrate from various wood particle sizes, organic amendments, and sand for desired physical properties and plant growth. HortScience 45:103-112.

Jenkins, J.R. and W.M. Jarrell. 1989. Predicting physical and chemical properties of container mixtures. HortScience 24:292-295.

Kaderabek, L.E. 2017. Effects of aging on the physical, chemical, and hydrologic properties of pine bark substrates. North Carolina State Univ., Raleigh, NC, Thesis.

Lea-Cox, J.D. and I.E. Smith. 1997. The interaction of air-filled porosity and irrigation regime on the growth of three woody perennial (Citrus) species in pine bark substrates. Proc. Southern Nurs. Assoc. Res. Conf. 42:169-174.
Mauseth, J.D. 1988. Plant anatomy. The Benjamin/ Cummings Publishing Co., Inc., Menlo Park, CA.

O'Meara, L., M.R. Chappell, and M.W. van Iersel. 2014. Water use of Hydrangea macrophylla and Gardenia jasminoides in response to a gradually drying substrate. HortScience 49:493498.

Pokorny, F.A. 1975. A physical characterization of pine bark used in six commercial nurseries. Proc. Southern Nurs. Assoc. Res. Conf. 20:2527.

Pokorny, F.A. 1979. Pine bark container mediaan overview. Proc. Inter. Plant Prop. Soc. 29:484-495.

Puustjarvi, V. and R.A. Robertson. 1975. Physical and chemical properties, p. 23-38. In: D.W. Robinson and J.G.D. Lamb (eds.). Peat in horticulture. Academic Press, London, UK.
Reed, D.Wm. 1996. Water, media, and nutrition for greenhouse crops. Ball Publishing, Batavia, IL.

Richards, D., M. Lane, and D.V. Beardsell. 1986. The influence of particle-size distribution in pinebark:sand:brown coal potting mixes on water supply, aeration and plant growth. Scientia Hort. 29:1-14.

Stephens, D.B. and K.R. Rehfeldt. 1985. Evaluation of closed-form analytical models to calculate conductivity in a fine sand. Soil Sci. Soc. Amer. J. 49:12-19.

Thompson, W.H. 2002. Test methods for the examination of composting and compost. US Composting Council, Holbrook, NY.

Van Genuchten, M.T. 1980. A closed-form equation for predicting the hydraulic conductivity of unsaturated soils. Soil Sci. Soc. Amer. J. 44:892-898. 